\title{
The assignment of workers to tasks, wage distribution and technical change: a critical review
}

Citation for published version (APA):

Dupuy, A. (2008). The assignment of workers to tasks, wage distribution and technical change: a critical review. IZA. IZA Discussion Paper Series No. 3379 http://ftp.iza.org/dp3379.pdf

Document status and date:

Published: 01/01/2008

Document Version:

Publisher's PDF, also known as Version of record

\section{Please check the document version of this publication:}

- A submitted manuscript is the version of the article upon submission and before peer-review. There can be important differences between the submitted version and the official published version of record.

People interested in the research are advised to contact the author for the final version of the publication, or visit the DOI to the publisher's website.

- The final author version and the galley proof are versions of the publication after peer review.

- The final published version features the final layout of the paper including the volume, issue and page numbers.

Link to publication

\footnotetext{
General rights rights.

- You may freely distribute the URL identifying the publication in the public portal. please follow below link for the End User Agreement:

www.umlib.nl/taverne-license

Take down policy

If you believe that this document breaches copyright please contact us at:

repository@maastrichtuniversity.nl

providing details and we will investigate your claim.
}

Copyright and moral rights for the publications made accessible in the public portal are retained by the authors and/or other copyright owners and it is a condition of accessing publications that users recognise and abide by the legal requirements associated with these

- Users may download and print one copy of any publication from the public portal for the purpose of private study or research.

- You may not further distribute the material or use it for any profit-making activity or commercial gain

If the publication is distributed under the terms of Article $25 \mathrm{fa}$ of the Dutch Copyright Act, indicated by the "Taverne" license above, 


\title{
The Assignment of Workers to Tasks, Wage Distribution and Technical Change: A Critical Review.*
}

\author{
Arnaud Dupuy ${ }^{\dagger}$
}

February 15, 2008

\begin{abstract}
This paper reviews the literature on two-sided atomeless assignment models of workers to tasks. Using simple parametric examples, the fundamental differences between the comparative advantage and the scale of operations models are illustrated. Holding the distributions of abilities and tasks and the production function of worker-task pairs constant, the two principles are shown to produce different wage distributions and wage inequality. These models are useful to evaluate the general equilibrium effect of technical change on the wage structure. In all models, skilled-biased technical change that impacts the production function of worker-task pairs lead to rising wage inequality. JEL Classification: D3, J3 and O3.

Keywords: Assignment models, Wage structure, technical change.
\end{abstract}

*The comments of Bart Golsteyn, Ben Kriechel, Raymond Montizaan and an anonymous referee are acknowledged.

${ }^{\dagger}$ Corresponding address: ROA and Maastricht University, PO Box 616, NL6200 MD, The Netherlands. Email: a.dupuy@roa.unimaas.nl. 


\section{Introduction}

Consider a labor market where workers are heterogenous with respect to their ability. Similarly, tasks, that are owned by firms, are heterogenous with respect to their difficulty. To produce output, tasks need to be performed by workers. Two central questions arise in this market. First, which worker performs what task? Second, what are the equilibrium payoffs? Two-sided atomeless assignment models answer these two questions simultaneously. These models ${ }^{1}$ focus on the relationship between the distribution of abilities, the distribution of tasks and the resulting equilibrium payoffs functions. This relationship makes two-sided atomeless assignment models particularly attractive to analyze the wage structure as a function of the distribution of abilities. Moreover, while there are $N$ ! different possible assignments in an economy with $N$ workers and $N$ tasks, the assignment that prevails in equilibrium will depend on the production function of worker-task pairs. This relationship makes two-sided atomeless assignment models particularly attractive to analyze changes in the wage structure as technology evolves over time.

This paper reviews the literature on two-sided atomeless assignment models of workers to tasks. Two groups of models can be distinguished according to the principle that governs assignment, i.e. comparative advantage principle or scale of operations principle. As Sattinger (1984, 1993) already highlighted, both principles differ in the location of flexibility in the economy. In the comparative advantage model, workers are perfect substitutes but the output of tasks must be produced in fixed proportions. In the scale of operations model, there is no substitution possibility between workers but the output of tasks are perfect substitutes. In this paper, I propose to use simple parametric examples to illustrate the fundamental differences between the comparative advantage and the scale operations models. I will show that both principles yield different wage functions in equilibrium and this, even

\footnotetext{
${ }^{1}$ The assignment literature diverges from the matching theory, see Mortensen (1986) for instance, and search theory, (see Jovanovic (1979), Diamond (1981) and Pissarides (1984)) by assuming that workers have full knowledge of all employers' wage offers and that employers have full knowledge of all workers' abilities. In assignment models, it is assumed that free choice and competitive markets assign tasks to workers efficiently. Perfect competition ensures that workers are rewarded according to their marginal productivity. Free choice ensures that workers are efficiently assigned to tasks. Recently, some attempts have been made towards incorporating search frictions into assignment models, e.g. Sattinger (1995), Burdett and Coles (1997), Shimer and Smith (2000) and Shimer (2003, 2005).
} 
when the distribution of abilities and tasks and the production technology are identical. In particular, I will show that the two principles lead to differences in wage inequality in equilibrium.

Assignment models are very useful to model the impact of technical change on the wage distribution. The most common approach in the literature has been to consider changes in the production function parameters over time. For instance, Teulings (1995) and Costrell and Loury (2004) have shown, among other, that skilled-biased technical change captured by an increase in the production function of worker-task pairs leads to an increase in wage inequality. Yet, technical change could also operate through changes in the distribution of tasks or machines over time. Although this last type of technical change has been less studied in the literature, recent empirical evidence about job polarization by Autor et al. (2006), Goos and Manning (2007) and Spitz-Oener (2006) suggests it has empirical support. Technical change captured by an increase in the mean task leads to an increase in the wage of all workers but also an increase in wage inequality.

Closely related to the models discussed in this paper is the burgeoning literature about one-sided atomeless assignment models. In these models, there is only one type of heterogenous agents ${ }^{2}$ and two types of assignment occur. First, depending on their abilities, agents are assigned to be either a worker or a manager. After this initial assignment, groups of workers are assigned to managers. Equilibrium in these models is characterized by a mapping function that maps ability to occupations, a mapping function that maps teams of different sizes, where size is measured in efficiency units (number of workers $\times$ ability level) to managers of different abilities and a monotonic wage function so that the most able worker earns less than the least able manager, there is no overlap between the earnings of workers and managers. In equilibrium, managers of higher ability run larger firms. Among others, Lucas (1978), Rosen (1982), and more recently Fox (2006) used these models to explain the distribution of firms size, the effect of firm-size on earnings or the earnings of superstars as Rosen (1981). Garicano (2000), Garicano and Rossi-Hansberg (2004) and (2006) developed one-sided assignment models designed to explain changes in wages, hierarchical structure and firm-size as communication costs decrease through technical change. In their model, firm-size is not restricted to be expressed in efficiency units anymore. The

\footnotetext{
${ }^{2}$ Lucas (1978) considers two types of (inputs) agents: capital and workers. in Lucas's model, only workers are heterogenous though.
} 
model allows us to distinguish between the number and the ability level of workers assigned to managers. They show that in equilibrium, abler managers will supervise larger teams of higher ability.

The remaining structure of the paper is as follows. Section 2 provides some preliminary definitions. Section 3 presents the comparative advantage model. Section 4 presents the scale of operations model. Section 5 compares the wage distribution derived from both models. Section 6 focuses on the impact of technical change on the distribution of wages in the various models. Section 7 concludes.

\section{Definitions}

In the various models discussed in this paper, the supply side of the economy is characterized by workers who are heterogenous with respect to a single cardinal one-dimensional measure. This measure matters for performing tasks, jobs or operating machines. However, in the various papers surveyed this measure has been given different names. Sattinger (1975) refers to this measure as grades while Sattinger $(1979,1993)$ and Costrell and Loury (2004) refer to ability and Teulings $(1995,2005)$ uses the term skills. In this paper, I will use the term ability to define this supply side measure.

On the other side of these two-sided assignment models, demand is characterized by a single cardinal one-dimensional measure. Just as workers' characteristics, the demand side characteristic matters for productivity. Sattinger (1975) refers to this demand side measure as tasks whereas Sattinger $(1979,1993)$ refers to machines and Costrell and Loury (2004) and Teulings $(1995,2005)$ use the term job. In this paper, I will use both the term task and the term machine interchangeably to define this demand side measure. The term task is generic to all models but in the differential rents model it is preferable to talk about machines when we refer to the associated rents.

One may wrongly believe that the assignment of workers to tasks is always driven by the structure of comparative advantage. In fact, as Sattinger (1984, 1993) already highlighted, there are two distinct principles governing the assignment of workers to tasks in the literature besides comparative advantage. The first alternative to comparative advantage to determine the assignment of workers to tasks is preferences. Tinbergen (1956) developed a model in which the assignment of workers to jobs is driven by workers' preferences for performing certain tasks. Wage differentials in this model arise 
as compensating differentials rather than productivity differentials. Since this paper focuses on the impact of technological change in assignment models, Tinbergen's (1956) allocation model, which focuses on preferences rather than technology, will not be treated in this paper.

Yet, the scale of operations model provides a third principle that may govern the assignment of workers to tasks. As in the comparative advantage model, in the scale of operations model, wage differentials arise from productivity differences. However, the scale of operations and the comparative advantage principles differ essentially in the technology available to produce output, although not necessarily in the production function of worker-task pairs. While in the comparative advantage model, the output of each task is required in fixed proportions, there is perfect substitution between the output of each task in the scale of operations. Moreover, while a particular task could be performed by an indefinite number of workers in the comparative advantage model, workers are needed in fixed proportions at each task in the scale of operations model. Hence, both models differ in the location of the flexibility in the economy. In the comparative advantage model, there is perfect flexibility at the task level but aggregate output is produced with fixed proportions of the output of each task, while in the scale of operations effect, aggregate output is produced with perfect substitutability of the output at each task but the output at each task must be produced with fixed proportions of workers.

\section{Comparative advantage}

\subsection{Sattinger 1975}

In his influential paper, Sattinger (1975) developed a model that describes the assignment of workers with different abilities to heterogenous tasks. He showed that a sufficient condition for the wage distribution to be different from the distribution of productivity, is the presence of workers comparative advantage in productivity. Frictions of any sorts are not necessary.

Formally, let $t$ be a worker's ability and let $s(t)$ be the density distribution of abilities in the economy. The economy is assumed to be large enough so that $s(t)$ is continuous on an interval. Similarly, let $v$ be a task to be performed in a single firm and let $d(v)$ be the density distribution of tasks. Tasks differ in their difficulty and without loss of generality, assume that the 
difficulty of tasks increases with $v$.

Assume perfect information, so that firms know $s(t)$ and workers know $d(v)$, and competition so that no single firm and no single worker can affect wages. Assume further that workers work the same amount of hours per period and that tasks are divisible. Although firms choose which tasks they want to have performed based on the costs of having them performed and the production resulting from these tasks, in equilibrium, firms do not seek to have a different task performed. This means that, given the distribution of tasks, we can infer the assignment of workers to tasks and hence the distribution of wages.

To equilibrate demand and supply, each worker needs to be assigned to a task and each task needs to be assigned a worker. Suppose there are $N$ workers and $N$ tasks in this economy. This means that there are $N$ ! possible assignments. Sattinger (1975) proved that if the density distribution of ability and tasks are continuous and if workers with higher ability have a comparative advantage in more difficult tasks, then the equilibrium assignment is the one for which workers with higher ability perform more difficult tasks, i.e. $v=v(t)$ with $v^{\prime}(t)>0$.

Let $c(v, t)$ be the time it takes a worker with ability $t$ to perform task $v$. The function $r(v, t)=\frac{1}{c(v, t)}$ is by definition the productivity of a worker with ability $t$ at task $v$. Comparative advantage means that $c$ is $\log$ submodular, i.e. $\frac{\partial^{2} \ln c(v, t)}{\partial v \partial t}<0$ and therefore that $r(v, t)$ is $\log$ supermodular, i.e. $\frac{\partial^{2} \ln r(v, t)}{\partial v \partial t}>0$. Let $w(t)$ be the wage of a worker with ability $t$. The costs of having task $v$ performed by worker with ability $t$ is given by $C=w(t) c(v, t)$. Firms minimizing costs will therefore seek the level of ability $t^{*}$ so that:

$$
\begin{aligned}
w^{\prime}\left(t^{*}\right) c\left(v, t^{*}\right)+w\left(t^{*}\right) \frac{\partial c\left(v, t^{*}\right)}{\partial t} & =0 \\
-\frac{\partial \ln c\left(v, t^{*}\right)}{\partial t} & =\frac{\partial \ln w\left(t^{*}\right)}{\partial t}
\end{aligned}
$$

To see why it is the structure of comparative advantage and not absolute advantage that drives the assignment of more able workers to more complex jobs, consider the second order condition to costs minimization. The first order condition spelled out above will be costs minimizing if and only if costs are convex or $\frac{\partial^{2} C}{\partial t^{2}}>0$. This reads as: 


$$
\begin{aligned}
{\left[\frac{\partial^{2} \ln c(v, t)}{\partial t^{2}}\right]_{v=v(t)}+\frac{\partial^{2} \ln w(t)}{\partial t^{2}} } & >0 \\
v^{\prime}(t)\left[\frac{\partial^{2} \ln c(v, t)}{\partial v \partial t}\right]_{v=v(t)} & <0
\end{aligned}
$$

since using the first order condition we have $\frac{\partial^{2} \ln w(t)}{\partial t^{2}}=-\left[\frac{\partial^{2} \ln c(v, t)}{\partial t^{2}}\right]_{v=v(t)}-$ $v^{\prime}(t)\left[\frac{\partial^{2} \ln c(v, t)}{\partial v \partial t}\right]_{v=v(t)}$.

Hence, as long as the costs function is log submodular $\left[\frac{\partial^{2} \ln c(v, t)}{\partial v \partial t}\right]_{v=v(t)}<$ 0 , i.e. as long as there is comparative advantage, more skilled workers with be assigned to more complex tasks in equilibrium and $v^{\prime}>0$.

Substituting $v(t)$ for $v$ in the first order condition 1 and integrating over a range of ability, we obtain the fundamental equation that links wage differentials $\frac{\partial \ln w\left(t^{*}\right)}{\partial t}$, and hence the distribution of wages, to the assignment of workers to tasks defined by $v(t)$.

$$
\begin{aligned}
\int_{t_{1}}^{t_{2}}-\left[\frac{\partial \ln c\left(v, t^{*}\right)}{\partial t}\right]_{v=v(t)} d t & =\int_{t_{1}}^{t_{2}} \partial \ln w\left(t^{*}\right) \\
\int_{t_{1}}^{t_{2}}\left[\frac{\partial \ln r\left(v, t^{*}\right)}{\partial t}\right]_{v=v(t)} d t & =\int_{t_{1}}^{t_{2}} \partial \ln w\left(t^{*}\right)
\end{aligned}
$$

The wage differential between workers with abilities $t_{1}$ and $t_{2}$, with $t_{2}>t_{1}$, is larger than the productivity differential between the two workers holding the task constant. Since $v^{\prime}(t)>0$, wage differentials in this model arise from ability differentials, magnified by the assignment of abler workers to more difficult, hence more rewarded, tasks. The wage distribution will therefore be skewed to the right compared to the distribution of productivity at any given task. Integrating equation 2 over $t$ yields the equilibrium (log) wage function $\ln w(t)$. Since $\ln w(t)$ is monotonic, its inverse $t(\ln w)$ is well defined. Performing the change of variables $t(\ln w)$ and noting that $d t=\frac{t^{\prime}(\ln w) d w}{w}$, the density distribution of wages in equilibrium is derived as: 


$$
l(w)=\frac{s(t(\ln w)) t^{\prime}(\ln w)}{w}
$$

Example 1. To illustrate this model, consider the following simple example. $^{3}$ Suppose $r(v, t)=\exp (\delta v t)$ with $\delta>0$. This functional form is log supermodular hence, abler workers have a comparative advantage in difficult tasks. Therefore, in equilibrium, abler workers will be assigned to more difficult tasks. Suppose further that abilities and tasks follow uniform distributions, $s(t)=\frac{1}{\bar{t}-\underline{t}}$ and $t \in[\underline{t}, \bar{t}]$ with $0 \leq \underline{t}<\bar{t}<\infty$ and $d(v)=\frac{1}{\bar{v}-\underline{v}}$ and $v \in[\underline{v}, \bar{v}]$ with $0 \leq \underline{v}<\bar{v}<\infty$.

Under the $\log$ supermodularity of $r(.,$.$) , the mapping function v(t)$ is retrieved from the density functions as follows:

$$
\begin{aligned}
\int_{v}^{\bar{v}} \frac{1}{\bar{v}-\underline{v}} d x & =\int_{t}^{\bar{t}} \frac{1}{\bar{t}-\underline{t}} d x \\
\frac{v}{\bar{v}-\underline{v}} & =\frac{t}{\bar{t}-\underline{t}} \\
& \Leftrightarrow \\
v & =v(t)=\Lambda t
\end{aligned}
$$

where $\Lambda=\frac{\bar{v}-\underline{v}}{\bar{t}-\underline{\underline{t}}}$.

It immediately follows from this result that when both ability and tasks follow the same distribution $\bar{t}=\bar{v}$ and $\underline{t}=\underline{v}$, the mapping function in equilibrium is the identity function. Using the parametric expressions of $v(t)$ and $r(v, t)$ in equation 2 , the log wage as a function of ability $t$ is given by:

$$
\ln w(t)=\int_{\underline{t}}^{t} \delta \Lambda t d t=\ln w_{0}+\frac{\delta \Lambda}{2}\left(t^{2}-\underline{t}^{2}\right)
$$

where $\ln w_{0}$ is a constant of integration.

\footnotetext{
${ }^{3}$ This example was not chosen for its realistic feature but rather for the sake of illustration and comparability with other models. I chose uniform distributions for they yield closed form solutions for all models depicted in this paper (except Teulings (1995)). Using similar distributions of abilities across models has the advantage of keeping track of the essential source of differences between the various models, i.e. the technology of production.
} 
The wage function is identified up to a constant of integration. The model could be closed using an exogenous reservation wage for workers, say $\widetilde{w}$, so that $\ln w_{0}=\ln \widetilde{w}$ guarantees full employment of workers.

Performing the change of variables $t(\ln w)$ and noting that $d t=\frac{t^{\prime}(\ln w) d w}{w}$, the density distribution of wages in equilibrium is derived as:

$$
l(w)=\frac{1}{\delta \Lambda} \frac{1}{w} \frac{1}{t(\ln w)}
$$

where $t(\ln w)=\left(\frac{2}{\delta \Lambda} \ln \frac{w}{\widetilde{w}}+\underline{t}^{2}\right)^{1 / 2}$.

\subsection{Extension: Teulings 1995 and 2005}

A particularly interesting extension of Sattinger (1975)'s model was developed in Teulings (1995). Teulings (1995) departs from Sattinger's task assignment model by allowing the distribution of tasks to be endogenously determined in equilibrium. This is of importance for recent empirical evidence shown by Autor et al. (2006) and Goos and Manning (2007) indicate a job polarization in the US and UK. Although one could simply change exogenously the distribution of tasks in Sattinger's model and reevaluate the equilibrium assignment, endogenizing the distribution of tasks has the advantage of taking into account the general equilibrium effect of technical change. In Teulings's model, technological change affecting the productivity of worker-task pairs will not only affect wages but also the demand for the output of the various task. As the demand for the product of the various tasks changes, the equilibrium distribution of tasks changes .

To endogenize $d(v)$, consider that each task produces a commodity that is traded in the good market at the price $p(v)$. Each commodity is meant for consumption purposes only. Workers/consumers have an identical homothetic continuous CES utility function that captures their love for product variety.

$$
U=\left(\int_{\tau}^{\infty} q(v) f_{s}(v)^{-(\eta-1)} d v\right)^{-1 /(\eta-1)}
$$

where $f_{s}(v)$ is the density of commodity $v$ (supplied in the good market) produced, $q(v)$ are exogenous weights for the various commodities and $1 / \eta$ is the elasticity of substitution between the various commodities. 
Assuming free entry and perfect competition, firms pay workers their marginal contribution to output. Defining $r(v, t)$ the productivity of workers with ability $t$ at task $v$, this means that $p(v) r(v, t)-w(v, t)=0$. Moreover, since only the consumption of goods matters for workers, workers will choose the task that maximizes their earnings. Earnings maximization yields the additional condition $\frac{\partial w(v, t)}{\partial v}=p^{\prime}(v) r(v, t)+p(v) \frac{\partial r(v, t)}{\partial v}=0$.

As in Sattinger (1975), if $r(v, t)$ is log supermodular, workers with higher ability have a comparative advantage in complex tasks. Assuming that workers with different abilities are perfect substitutes within jobs, equilibrium will therefore be characterized by a strictly increasing mapping function $t(v)$. The density of jobs in equilibrium is derived from the density of ability and the first derivative of the mapping function as $d(v)=s(t(v)) t^{\prime}(v)$ and the density of commodity of $v$ produced is given by $f_{s}(v)=s(t(v)) t^{\prime}(v) r(v, t(v))$.

Equilibrium in the goods market is achieved when consumers maximize their utility as defined in equation 4 given the budget constraint:

$$
M \geq \int_{\tau}^{\infty} f_{d}(v) p(v) d v
$$

where $f_{d}(v)$ is the density of commodity $v$ demanded and $M$ is disposable income.

Utility maximization yields $p(v)=Y^{\eta} g(v) f_{d}(v)^{-\eta}$, which using the free entry condition $p(v) r(v, t)=w(t)$, the earnings maximization condition $p^{\prime}(v) r(v, t)+p(v) \frac{\partial r(v, t)}{\partial v}=0$, the equilibrium condition on the good market $f_{d}(v)=f_{s}(v)=f(v)$, differentiating with respect to $v$ and substituting $s(t(v)) t^{\prime}(v) r(v, t(v))$ for $f(v)$ yields:

$$
\frac{t^{\prime \prime}}{t^{\prime}}+\frac{\partial r / \partial t}{r}+\frac{s^{\prime} t^{\prime}}{s}=\frac{1-\eta}{\eta} \frac{\partial r / \partial v}{r}+\frac{1}{\eta} \frac{q^{\prime}}{q}
$$

This equation is a second order differential equation. Solving this equation gives the mapping function $t(v)$ and hence the wage function. Closed form solutions for this differential equation do not exist. However, Teulings showed that with some additional assumptions on $r(v, t), g(v)$ and $s(t)$, a closed form solution exists for the wage function conditional on the mapping function $v(t)$. 
In this model, the distribution of wages will be relatively skewed to the right compared to the distribution of productivity, as in Sattinger (1975), as the assignment is principally driven by comparative advantage.

Through simulations, Teulings (2005) was also able to show that the wage distribution compresses as the mean ability increases in the economy. In this model, the ease to substitute between workers depends on the ability differential between workers. The larger the distance in ability between two workers the harder it becomes to substitute one for another (see Teulings (2005)).

Example 2. Assume ${ }^{4}$ that $r(v, t)=\exp (\delta v t)$ with $\delta>0, g(v)=\exp (\omega+$ $(\eta-1) \lambda v)$ with $\eta>1, \lambda, \omega \in R$ and $s(t)$ is uniform on $[\underline{t}, \bar{t}]$. Moreover, assume $v \in[\underline{v}, \bar{v}]$.

The mapping function is then the solution of:

$$
v^{\prime \prime}(t)=\frac{\eta-1}{\eta}(\delta t-\lambda) v^{\prime}(t)^{2}+\delta v(t) v^{\prime}(t)
$$

To solve this second order differential equation requires two initial conditions. These two initial conditions are: $v(\underline{t})=\underline{v}$ and $v(\bar{t})=\bar{v}$.

The wage function conditional on the mapping function $v(t)$ reads as:

$$
w(t)=\omega+\eta \ln Y-(\eta-1)(\delta t-\lambda) v(t)+\eta \ln v^{\prime}(t)
$$

\section{Scale of operations}

\subsection{Sattinger 1979 and 1993}

Sattinger $(1979,1993)$ generalizes Ricardo's differential rents model to the case of two heterogenous collaterals, i.e. workers and tasks. In his differential rents model, tasks are associated with a unit of capital, a machine for the sake of the argument. Each task refers to a different machine and each machine needs to be operated by fixed proportions of workers, i.e. one and only one worker, to produce output. The level of output produced by a machine $v$

\footnotetext{
${ }^{4}$ Teulings (1995) derived the second order differential equation of $v(t)$ and the wage function using the same setting but assuming a normal distribution of abilities rather than a uniform distribution.
} 
when operated by worker $t$ is given by $r(v, t)$. Assume that $r$ has continuous first and second order partial derivatives and that $\frac{\partial r}{\partial v}, \frac{\partial r}{\partial t}>0$.

As in the comparative advantage model, the economy is assumed to be perfectly competitive, large enough so that the density distribution of machines and workers can be assumed to be continuous on an interval. Without loss of generality, let the support of $t$ and $v$ be $[\underline{t}, \bar{t}]$ and $[\underline{v}, \bar{v}]$ respectively. Assume further that the measures of machines and workers are equal for simplicity.

To derive the general equilibrium of this model, Sattinger (1979) assumes that under the period considered, the distribution of machines is exogenous, i.e. does not depend on wages. This assumption is equivalent to assuming that firms first invest in capital before entering the labor market. This structure looks like the Putty-Clay structure. The hold-up problem inherent to this structure is prevented by assuming perfect information.

With this exogeneity assumption, the general equilibrium of this model is derived in three steps. In the first step, one makes a tentative assumption about the assignment of workers to tasks in equilibrium. The second step consists to derive the associated equilibrium wages for this assignment. Finally, in the third step, one checks whether the second order conditions for equilibrium are satisfied by the equilibrium wages derived in step 2 .

Step 1: Tentative tasks assignment

Consider the assignment of more productive workers to more productive machines. This assignment results in a mapping function $v$ that associates to each value of ability $t$ a single value of machine $v \in[\underline{v}, \bar{v}]$, i.e. $v=v(t)$ with $v^{\prime}>0$. The function $v$ is monotonic, increasing on $t \in[\underline{t}, \bar{t}]$ since abler workers are assigned to more productive machines in equilibrium.

The density of workers' ability can therefore directly be derived from the density of machines by performing the transformation of variables $v=v(t)$ and noting that $d v=v^{\prime}(t) d t$. This yields:

$$
\int_{v(\underline{\underline{t}})}^{v(\bar{t})} d(v(t)) v^{\prime}(t) d t=\int_{\underline{\underline{t}}}^{\bar{t}} s(t) d t=1
$$

The density of individuals with ability $t$ is therefore $s(t)=d(v(t)) v^{\prime}(t)$. This is a first order nonlinear nonautonomous differential equation. 
Step 2: Equilibrium wages and rents

The owner of machine $v$ seeks to maximize the profits derived from its machine. The profits from assigning a worker with ability $t$ are $r(v, t)-$ $w(t)$. The owner will therefore compare the productivity increase to the wage increase associated to a worker with higher ability $t$. This yields the following first order condition:

$$
\frac{\partial r(v, t)}{\partial t}=w^{\prime}(t)
$$

Note that from the assumption that $\frac{\partial r}{\partial t}>0$, we therefore have $w^{\prime}(t)>0$.

The equilibrium rents are obtained in a similar fashion by noting that earnings are given by $w(t)=r(v, t)-\pi(v)$. Earnings maximization leads workers supplying ability $t$ to compare the productivity increase to the rent increase associated to a machine ranked to the left or the right of $v$. Hence, the first order conditions to earnings maximization are given by:

$$
\frac{\partial r(v, t)}{\partial v}=\pi^{\prime}(v)
$$

Equations 7 and 8 give respectively the wage differential at task $v$ and the rent differential at ability $t$. These wage and rent differentials do not hold for values of $t$ other than $t=v^{-1}(v)$ and therefore depend on the equilibrium assignment. Evaluating the differential equation 7 for $v=v(t)$ and integrating over $t$ yields the wage function. Evaluating the differential equation 8 for $t=v^{-1}(v)$ and integrating over $v$ yields the rents function.

\section{Step 3: Second order conditions}

The tentative assignment defined in step 1 is a valid one only when the firms' second order condition to profits maximization and the workers' second order conditions to earnings maximization, that is profits are concave in $t$ and earnings are concave in $v$, are satisfied. Put in equation, the second order condition for profits maximization reads as: 


$$
\begin{aligned}
{\left.\left[\frac{\partial^{2} r(v, t)}{\partial t^{2}}\right]_{v=v(t)}-w^{\prime \prime}(t)\right) } & <0 \\
-\left[\frac{\partial^{2} r(v, t)}{\partial t \partial v} v^{\prime}\right]_{v=v(t)} & <0
\end{aligned}
$$

since $w^{\prime \prime}(t)=\left[\frac{\partial^{2} r(v, t)}{\partial t^{2}}\right]_{v=v(t)}+\left[\frac{\partial^{2} r(v, t)}{\partial t \partial v} v^{\prime}(t)\right]_{v=v(t)}$.

The second order conditions for earnings maximization read as:

$$
\begin{aligned}
{\left[\frac{\partial^{2} r(v, t)}{\partial v^{2}}\right]_{t=v^{-1}(v)}-\pi^{\prime \prime}(v) } & <0 \\
-\left[\frac{\partial^{2} r(v, t)}{\partial t \partial v} \frac{1}{v^{\prime}}\right]_{t=v^{-1}(v)} & <0
\end{aligned}
$$

since $\pi^{\prime \prime}(v)=\left[\frac{\partial^{2} r(v, t)}{\partial v^{2}}\right]_{t=v^{-1}(v)}+\left[\frac{\partial^{2} r(v, t)}{\partial t \partial v} \frac{1}{v^{\prime}}\right]_{t=v^{-1}(v)}$.

Since $v^{\prime}>0$ these second order conditions therefore imply that:

$\left[\frac{\partial^{2} r(v, t)}{\partial t \partial v}\right]_{v=v(t)}>0$. Hence, as long as the cross derivative $\frac{\partial^{2} r(v, t)}{\partial t \partial v}$ is positive, that is as long as workers and machines characteristics are complements, an assignment where abler workers get more productive machines, i.e. $v^{\prime}>0$, is valid.

\section{Equilibrium pricing functions}

Evaluating the differential equation 7 at $v=v(t)$ and integrating over $t$ yields the wage function.

$$
w(t)=w_{0}+\int_{\underline{t}}^{t}\left[\frac{\partial r(v, x))}{\partial x}\right]_{v=v(x)} d x
$$

where $w_{0}$ is a constant of integration. 
Similarly, evaluating the differential equation 8 at $t=v^{-1}(v)$ and integrating over $v$ yields the rent function as follows:

$$
\pi(v)=\pi_{0}+\int_{\underline{v}}^{v}\left[\frac{\partial r_{k}(x, t)}{\partial x}\right]_{t=v^{-1}(x)} d x
$$

where $\pi_{0}$ is a constant of integration.

The wage and rent functions are identified up to constants of integration. Following Sattinger (1979), the model is closed by specifying exogenous reserve prices for the marginal worker and machine. For the least able workers to be indifferent between being assigned to machine 1 or remaining unemployed we need $w(\underline{t})=w_{0}=\widetilde{w}>0$ where $\widetilde{w}$ is the reservation wage. Firms owing machines 0 will be indifferent between employing the least able worker or withholding the machine from the market if $\pi(\underline{v})=\pi_{0}=r(\underline{v}, \underline{t})-\widetilde{w}=\tilde{\pi}$ where $\widetilde{\pi}$ is the reserve price for the owner of capital.

Once again, since $w(t)$ is monotonic, its inverse $t(w)$ is well defined. Performing the change of variables $t(w)$ and noting that $d t=t^{\prime}(w) d w$, the density distribution of wages in equilibrium is derived as:

$$
l(w)=s(t(w)) t^{\prime}(w)
$$

The differential rents model is a particularly interesting tool to investigate the source of (rising) wage inequality. Recently, Gabaix and Landier (2008) and Terviö (2008) have applied the model to the case of CEO pay. Both studies show that CEO pay differentials are principally due to differences in tasks performed by CEOs, i.e. the size of the firm managed by CEOs, and not so much to skills differentials. Indeed, Terviö (2008) provides contrafactual results showing that CEO pay differentials would be reduced considerably if all CEO's were running firms of similar size, whereas CEO pay differentials would remained roughly constant if all firms were ran by CEO's of same ability. Moreover, looking at changes over time, both studies conclude that the rise in CEO pay differentials over time are merely due to the rise in the dispersion of firm-size. 
Example 3. To illustrate the model I propose a very simple example. ${ }^{5}$ Suppose $r(v, t)=\exp (\delta v t)$ with $(a, b) \in(0,1)^{2}$ and $t \in[\underline{t}, \bar{t}]$ with $0 \leq \underline{t}<\bar{t}<$ $\infty$ and $d(v)=\frac{1}{\bar{v}-\underline{v}}$ and $v \in[\underline{v}, \bar{v}]$ with $0 \leq \underline{v}<\bar{v}<\infty$. This functional form satisfies: $\frac{\partial^{2} r(v, t)}{\partial t \partial v}=\left(\delta+\delta^{2} v t\right) \exp (\delta v t)>0$ so that an efficient assignment that assigns abler workers to more productive machines is valid. Note that the function is log supermodular, so that abler workers have a comparative advantage in more complex tasks. Suppose further that tasks and abilities follow uniform distributions, so that $s(t)=\frac{1}{\bar{t}-\underline{t}}$ and $d(v)=\frac{1}{\bar{v}-\underline{v}}$ as in example 1 .

The mapping function $v(t)$ is retrieved from the density functions as follows:

$$
\begin{aligned}
& \int_{v}^{\bar{v}} \frac{1}{\bar{v}-\underline{v}} d x=\int_{t}^{\bar{t}} \frac{1}{\bar{t}-\underline{t}} d x \\
& \frac{v}{\bar{v}-\underline{v}}=\frac{t}{\bar{t}-\underline{t}} \\
& v=v(t)=\Lambda t
\end{aligned}
$$

where $\Lambda=\frac{\bar{v}-\underline{v}}{\bar{t}-\underline{t}}$.

Using the expressions of $v(t)$ and $r(v, t)$ in equations 9 and 10 , the equilibrium wage and rent functions read as:

$$
\begin{aligned}
w(t) & =w_{0}+\int_{\underline{t}}^{t} \delta \Lambda t \exp \left(\delta \Lambda t^{2}\right) d x \\
& =\widetilde{w}+\frac{1}{2}\left(\exp \left(\delta \Lambda t^{2}\right)-\exp \left(\delta \Lambda \underline{t}^{2}\right)\right) \\
\pi(v) & =\pi_{0}+\int_{\underline{v}}^{v} \frac{\delta}{\Lambda} v \exp \left(\frac{\delta}{\Lambda} v^{2}\right) d x \\
& =\widetilde{\pi}+\frac{1}{2}\left(\exp \left(\frac{\delta}{\Lambda} v^{2}\right)-\exp \left(\frac{\delta}{\Lambda} \underline{v}^{2}\right)\right)
\end{aligned}
$$

\footnotetext{
${ }^{5}$ Sattinger (1979) derived closed form solutions when both abilities and machines are distributed according to distinct Pareto distributions.
} 
Performing the change of variables $t(w)$ and noting that $d t=t^{\prime}(w) d w$, the density distribution of wages in equilibrium is derived as:

$$
l(w)=\frac{1}{\delta \Lambda} \frac{1}{2(w-\widetilde{w})+\exp \left(\delta \Lambda \underline{t}^{2}\right)} \frac{1}{t(w)}
$$

where $t(w)=\left(\frac{1}{\delta \Lambda} \ln \left(2(w-\widetilde{w})+\exp \left(\delta \Lambda \underline{t}^{2}\right)\right)\right)^{1 / 2}$

\subsection{Extension: Costrell and Loury 2004}

The setting of the previous models emphasize a whole economy. This does not mean that these assignment models could not be used to study assignment within (large) firms. In the differential rents model presented above for instance, tasks could simply refer to tasks within a single firm. This is the approach taken in Costrell and Loury (2004). Costrell and Loury (2004) focus on the division of labor within firm so that each firm owns a continuum of machines, the same continuum for each firm. This contrasts to Sattinger's (1979) differential rents model where each firm owns a single machine. In this setting it seems natural to close the model assuming a free entry condition for firms. The free entry condition drives the firm's total profits to zero so that $\int_{\underline{v}}^{\bar{v}} \pi(v) d v=\int_{\underline{t}}^{\bar{t}}(p(v(t)) q(t)-w(t)) d t=0$. Assuming that the output production is multiplicatively separable, i.e. $r(v, t)=p(v) q(t)$, hence excluding the possibility for comparative advantage, and integrating equation 9 by parts yields:

$$
\begin{aligned}
w(t) & =w_{0}+\int_{\underline{t}}^{t} p(v(x)) q^{\prime}(x) d x \\
& =w_{0}+p(v(t)) q(t)-\int_{\underline{t}}^{t} v^{\prime}(x) p^{\prime}(v(x)) q(x) d x
\end{aligned}
$$

Using the zero-profit condition, we find:

$$
w_{0}=\frac{1}{\bar{t}-\underline{t}} \int_{\underline{t}}^{\bar{t}} \int_{\underline{t}}^{y} v^{\prime}(x) p^{\prime}(v(x)) q(x) d x d y
$$


Substituting into equation 11 obtains:

$$
\begin{aligned}
w(t)= & p(v(t)) q(t)+\frac{1}{\bar{t}-\underline{t}} \int_{\underline{t}}^{\bar{t}}\left(\int_{\underline{t}}^{y} v^{\prime}(x) p^{\prime}(v(x)) q(x) d x\right) d y \\
& -\int_{\underline{t}}^{t} v^{\prime}(x) p^{\prime}(v(x)) q(x) d x \\
= & p(v(t)) q(t)+\frac{1}{\bar{t}-\underline{t}} \int_{\underline{t}}^{\bar{t}} \int_{t}^{y} v^{\prime}(x) p^{\prime}(v(x)) q(x) d x d y
\end{aligned}
$$

The first term in equation 12 is the direct contribution of workers with ability $t$ to output. The second term is decreasing in ability $t$ so that lowwage workers earn more than their direct contribution to output whereas high-wage workers earn less than their direct contribution to output. This means that imposing a free entry condition leads to a wage profile that is flatter than the profile of the direct contribution to output.

Example 4. To derive $w_{0}$, using the free entry condition, as in Costrell and Loury, $r(v, t)$ needs to be multiplicatively separable. Consider $r(v, t)=$ $p(v) q(t)=v^{a} t^{b}$ where $p(v)=v^{a}$ and $q(t)=t^{b}$ with $(a, b) \in(0,1)^{2}$ and $t \in[\underline{t}, \bar{t}]$ with $0 \leq \underline{t}<\bar{t}<\infty$ and $d(v)=\frac{1}{\bar{v}-\underline{v}}$ and $v \in[\underline{v}, \bar{v}]$ with $0 \leq \underline{v}<\bar{v}<\infty$, $s(t)=\frac{1}{\bar{t}-\underline{t}}$ and $d(v)=\frac{1}{\bar{v}-\underline{v}}$. Note that Costrell and Loury (2004) consider the case where $b=1$. Since the density distributions are the same as in example 3 , so is the mapping function in equilibrium: $v=v(t)=\Lambda t$. The slope of the wage function is given by $b v^{a} t^{b-1}$ which evaluated at $v(t)=\Lambda t$ obtains $b \Lambda^{a} t^{a+b-1}$. Therefore, the wage function reads as:

$$
w(t)=w_{0}+\frac{b \Lambda^{a}}{a+b}\left(t^{a+b}-\underline{t}^{a+b}\right)
$$

where 


$$
\begin{aligned}
& w_{0}=\frac{1}{\bar{t}-\underline{t}} \int_{\underline{t}}^{\bar{t}} \int_{\underline{t}}^{y} a \Lambda^{a}\left(t^{a+b-1}-\underline{t}^{a+b}\right) d t d y \\
& =\frac{1}{\bar{t}-\underline{t}} \frac{a \Lambda^{a}}{a+b} \int_{\underline{t}}^{\bar{t}}\left(\left(y^{a+b}-\underline{t}^{a+b}\right)-\left(\underline{t}^{a+b} y-\underline{t}^{a+b+1}\right)\right) d y \\
& =\frac{1}{\bar{t}-\underline{t}} \frac{a \Lambda^{a}}{a+b}\left(\begin{array}{c}
\frac{1}{1+a+b}\left(\bar{t}^{a+b+1}-\underline{t}^{a+b+1}\right) \\
-\underline{t}^{a+b}(\bar{t}-\underline{t})-\frac{t^{a+b}}{2}\left(\bar{t}^{2}-\underline{t}^{2}\right)+\underline{t}^{a+b+1}(\bar{t}-\underline{t})
\end{array}\right) \\
& =\frac{a \Lambda^{a}}{a+b}\left(\frac{1}{1+a+b} \frac{\bar{t}^{a+b+1}-\underline{t}^{a+b+1}}{\bar{t}-\underline{t}}-\frac{\underline{t}^{a+b}}{2}(\bar{t}+\underline{t})-\underline{t}^{a+b}+\underline{t}^{a+b+1}\right)
\end{aligned}
$$

\section{Comparative advantage or scale of opera- tions?}

The assignment of workers to tasks can be either governed by the structure of comparative advantage or the scale of operations principle. Each principle, however, is characterized by a different technology and hence, yields a different wage function in equilibrium. This holds even when the distribution of abilities and tasks and the production function of worker-task pairs are identical. This fundamental difference is illustrated in example 1 and 3 . Given uniform distributions of abilities and tasks, equilibrium employment is characterized by the same mapping function of abilities to tasks as shown in Table 1. However, even assuming the same (exponential) production function of worker-task pairs in both models, the wage function as derived from an assignment of workers to tasks governed by the comparative advantage principle fundamentally differs from the wage function derived from the scale of operations principle.

How do the wage distributions between the two models differ? More specifically, does one model yield a larger wage inequality? The equilibrium minimum wage for both models is by definition $\widetilde{w}$. The slopes of the respective wage functions, however, are $\widetilde{w} \delta \Lambda t \exp \left(\frac{\delta \Lambda}{2}\left(t^{2}-\underline{t}^{2}\right)\right)$ for the comparative 
advantage model and $\delta \Lambda t \exp \left(\delta \Lambda t^{2}\right)$ for the scale of operations model. Taking the log of the ratio of these two expressions, the relative slope is equal to $\ln \widetilde{w}-\frac{\delta \Lambda}{2} t^{2}-\frac{\delta \Lambda}{2} t^{2}$. This function is strictly decreasing in ability. Hence, for a reservation wage larger than $\frac{\delta \Lambda}{2}\left(1+\underline{t}^{2}\right)$, the slope of the comparative advantage wage function will be larger than that of the scale of operations wage function everywhere on the support $[0,1]$ for all $\delta>0$ and $\Lambda>0$. It follows directly from this result that wage inequality will be relatively larger in the comparative advantage model than in the scale of operations model as indicated in Panel a of Figure 1. Similarly, for a reservation wage lower than unity, the slope of the comparative advantage wage function will be smaller than that of the scale of operations wage function everywhere on the support $[0,1]$ for all $\delta>0$ and $\Lambda>0$. As a result, the distribution of wages will be relatively less unequal for the comparative advantage model than for the scale of operations model. For intermediate cases, where $0<t\left(w^{*}\right)=\left(\frac{2}{\delta \Lambda} \ln \widetilde{w}-\underline{t}^{2}\right)^{1 / 2}<1$, wage inequality will be larger at the bottom of the distribution but lower at the top for the comparative advantage model compared to the scale of operations model as indicated on Panel b of Figure 1.

This simple example shows that although the distribution of tasks and skills and the productivity of worker-task pairs is the same in both settings, the wage structures need not be the same. Hence, the choice for one of the other method will not be neutral to wage inequality. The main difference between the two settings is about the factors of production. While labor is the only factor of production in the comparative advantage model, in the scale of operation model, both labor and capital are factors of production. From a conceptual point of view at least, having both capital (machines) and labor as factors of production seems to be more realistic. It appears therefore judicious to apply the scale of operations model to data where capital is an important factor in production, as Gabaix and Landier (2008) and Terviö (2008) have done in their studies of CEO pay, whereas the comparative advantage model would do just fine on data for which capital has a limit role in production.

\section{Technical change}

Although Sattinger (1975) was not primarily interested in the effect of technical change on wages, his model can be used to approach the question. It 
is straightforward from equation 2 that changes in the production function $r(v, t)$ will alter wage differentials and hence the curvature of the wage function and wage inequality. If technical change is skill-biased, that is if the increase in $r(v, t)$ over time is more pronounced for large $t$, then the wage differential between any two ability levels $t_{1}$ and $t_{2}$ with $t_{2}>t_{1}$ will increase over time and so will wage inequality as can be seen from equation 2 . In example 1, skilled-biased technical change of this form will increase parameter $\delta$ and hence, increase the slope of the wage function in equation 3 . Rising wage inequality will result.

In Teulings (1995), the effect of changes in the production function on wages is not as straightforward. As in Sattinger (1975), the direct effect of skill-biased technical change will be to increase wage differentials and hence wage inequality. However, as can be seen from equation 5, skill-biased technical change will also alter the second term of both sides of the equation. The impact will generally be different on both sides since the second term on the left hand side is $\frac{\partial r / \partial t}{r}=\frac{\partial \ln r(v, t)}{\partial t}$ while the second term on the right hand side is $\frac{\partial r / \partial v}{r}=\frac{\partial \ln r(v, t)}{\partial v}$. As a result, the shape of the mapping function will change. Since wages depend on the mapping function, technical change will also impact the wage function indirectly via the mapping function. The direct impact of skill-biased technical change on wages might be partly off-set by the induced changes in the mapping function. Note also that the change in the mapping function will in turn change the density distribution of tasks as $d(v)=s(t(v)) t^{\prime}(v)$.

Costrell and Loury (2004), in their application of Sattinger's (1979) differential rents model to within firm hierarchical tasks assignment, also considered the impact of technical progress on the production function. The type of production function they considered is multiplicatively separable, i.e. $r(v, t)=p(v) q(t)$, and $q(t)=t$. Hence, Costrell and Loury (2004) focuses on technical changes that manifest themselves into changes in the function $p(v)$ over time leaving $q(t)$ unaffected. This type of technical change improves the performance of machines independently of the person that operates this machine. If technical change is characterized by an increase in $p($.$) then the$ wage differential between any two workers with respective abilities $t_{1}$ and $t_{2}$ with $t_{2}>t_{1}$ widens over time. This result can be seen using equation 9 replacing $r(v, t)$ by $p(v) t$. The wage differential between workers with abilities 
$t_{1}$ and $t_{2}$ with $t_{2}>t_{1}$ is equal to $w\left(t_{2}\right)-w\left(t_{1}\right)=\int_{t_{1}}^{t_{2}} p(v(x)) d x$. Holding the distribution of abilities and tasks constant over time, the mapping function $v($.$) remains constant over time. Define k^{(s)}($.$) the function k($.$) at time s$ and assume that $p^{(2)}()>.p^{(1)}($.$) . Then we have:$

$$
\begin{aligned}
w^{(2)}\left(t_{2}\right)-w^{(2)}\left(t_{1}\right) & =\int_{t_{1}}^{t_{2}} p^{(2)}(v(x)) d x \\
& >\int_{t_{1}}^{t_{2}} p^{(1)}(v(x)) d x=w^{(1)}\left(t_{2}\right)-w^{(1)}\left(t_{1}\right)
\end{aligned}
$$

Hence, wage differentials at any ability levels will increase over time as $p($.$) increases over time.$

Although Costrell and Loury (2004) did not investigate the possibility of changes in the function $q($.$) , the consequences of an impact of technical$ change on $q($.$) are straightforward. In particular, suppose that technical$ change is skilled biased so that the productivity of abler workers increases relatively more than that of less able workers. This means that $q^{\prime(2)}()>$. $q^{\prime(1)}(.){ }^{6}$ Wage inequality will then increase everywhere on the support of ability. Indeed we have:

$$
\begin{aligned}
w^{(2)}\left(t_{2}\right)-w^{(2)}\left(t_{1}\right) & =\int_{t_{1}}^{t_{2}} p(v(x)) q^{\prime(2)}(x) d x \\
& >\int_{t_{1}}^{t_{2}} p(v(x)) q^{(1)}(x) d x=w^{(1)}\left(t_{2}\right)-w^{(1)}\left(t_{1}\right)
\end{aligned}
$$

Although, the above results are fundamental to understand the impact of technical change on the distribution of wages, the reviewed literature leaves

\footnotetext{
${ }^{6}$ Note that this condition implies $q^{(2)}()>.q^{(1)}($.$) . However, the condition q^{(2)}()>$. $q^{(1)}($.$) is not sufficient to guarentee that technical change will increase wage inequality$ everywhere as it does not guarentee that $q^{\prime(2)}()>.q^{\prime(1)}($.$) .$
} 
important questions open. For instance, the question of what the impact of changes in the distribution of tasks is on the distribution of wages? remains unanswered. This question is highly relevant at sight of the recent empirical evidence shown by Autor et al. (2006), Goos and Manning (2007) and SpitzOener (2006) indicating that the distribution of tasks has polarized in the 90s in the US, the UK and Germany, at the same time that wage inequality both within and between educational categories (college vs. high-school) increased.

This question has received little attention in the literature, probably due to the difficulty to derive generic results as changes in the distribution of tasks affect not only the equilibrium wage function but also the equilibrium mapping function. To my knowledge, only Suen (2007) studied the impact of changes in the distribution of tasks on wages. Using Sattinger's (1979) differential rents model with a multiplicatively separable production function of the form $r(v, t)=p(v) q(t)$, Suen (2007) investigated both the effect of an increase in the mean task holding other moments constant (first-order stochastic dominance) and an increase in the dispersion of the task distribution holding the mean task constant (second-order stochastic dominance) on the distribution of wages. Suen (2007) showed that an increase in the mean task will raise equilibrium wages of all workers but also raise wage differentials everywhere on the support of abilities. Suen (2007) also showed that an increase in the tasks dispersion will decrease the mean wage of workers, when $p(v)$ and $q(t)$ are concave. Even more generic is Suen (2007)'s result that the wage of all workers will decrease as the distribution of tasks becomes more dispersed over time. However, the current results from the assignment literature are silent about the impact of an increase in the dispersion of tasks on wage inequality. Suen's (2007) results make only predictions about monotonic movements of wages for all workers but not about the dispersion of wages.

\section{Remaining research questions}

Two-sided atomeless assignment models are very powerful to analyze (changes in) the wage structure. However, this literature, although following a long tradition, is rather under-documented, models remain quite restrictive and applications too scarce. At least two important research questions are left unanswered in the current literature. 
1. A growing body of empirical research led by Heckman and Rubinstein (2001) emphasizes the importance of both cognitive and noncognitive skills in explaining earnings. In contrast, assignment models in the literature assume that a single cardinal measure characterizes workers. Can two-sided assignment models accommodate for multiple dimensions of workers characteristics?

2. What is the relationship between aggregate output on the one hand and the distribution of tasks and abilities in the economy and the product of worker-task pairs on the other hand? In the literature about skillbiased technological change and rising skill-premium, a standard assumption is that aggregate production is of the Constant Elasticity of Substitution (CES) type and technical change is skilled-labor augmenting, leaving the elasticity of substitution between skilled and unskilled workers unaffected. ${ }^{7}$ However, this last assumption seems to be at odds with recent empirical evidence. Dupuy and Marey (2008) have shown that the elasticity of substitution between high-school and college graduates is not constant between 1964 and 2004 -it first decreased after 1978 and then increased after 1990- and Goldin and Katz (2007), using longer time series, documented a change in the elasticity of substitution between high-school dropouts and high-school graduates in 1949. This raises the question of what does the CES assumption imply for the distribution of tasks or what does the skilled-labor augmenting technical change imply for the evolution of the distribution of tasks over time?

Question 1 is addressed in Dupuy (2007a). Therein, I developed a general equilibrium assignment model with endogenous human capital formation and two dimensions of abilities. In this model educational choice together with the multidimensionality of skills ${ }^{8}$ generates wage distributions by education that, in general, will overlap. The general equilibrium feature of the model enables us to analyze simultaneously the effects of changes in the distribution of tasks and/or abilities on i) educational choice, and hence human capital formation, ii) the assignment of workers to tasks and iii) the structure of

\footnotetext{
${ }^{7}$ See Katz and Murphy (1992) and Acemoglu (2002) and references therein.

${ }^{8}$ Herewith, I use the term skills to refer to the transformation of abilities through education/training. Skills are the outcome of the education production whereas abilities are the input. In the model, workers are endowed with abilities of two types and self-select education to transform their abilities into marketable skills.
} 
wages. In the model, changes in the structure of wages arise from three separately identified sources: 1) changes in the distribution of skills, due to either improvements in the production of skills (schools quality improvement for instance) or changes in the distribution of endowed abilities (genetic inheritance and favorable family backgrounds), 2) changes in the distribution of jobs due to technological and organizational changes, and 3) changes in the productivity of worker-job matches, due to technical or organizational changes.

The first key feature of this model is that skills are endogenous and multidimensional. The endogeneity and multidimensionality of skills distinguish the model developed in this paper from previous general equilibrium assignment models in the literature that assume exogenous and unidimensional skills. Not only the multidimensionality is in accordance with the importance of noncognitive skills in explaining earnings, but it also explains why the wage distributions of workers with different education overlap.

The second key feature that distinguishes the model from the existing literature on assignment models is that two types of assignment occur. The first type of assignment is workers's educational self-selection. Workers are initially endowed with abilities of two types and can choose out of two types of education that each transforms abilities into marketable skills in different proportions. Educational self-selection endogenizes human capital formation. Workers specialize and supply their skills of the type that maximizes their earnings.

The second type of assignment is the assignment of workers to tasks. Each task refers to a different type of machine. To produce output, this machine needs to be operated by one and only one worker. Although the various machines can be operated by workers with different types and levels of skills, workers of different types and levels of skills differ in their productivity. For instance, suppose that the production function of worker-task pairs is so that i) workers of each skills type have a comparative advantage on a different side of the support of tasks, ii) within types of skills, more skilled workers have an absolute advantage and iii) workers' skills complement the characteristics of machines in production. Then, following Ricardo's principles of comparative advantage and differential rents, equilibrium in this model is characterized by two mapping functions, one for each type of skills supplied. The first mapping function is decreasing and maps skills of the first type to tasks on the left hand side of the support. The second mapping function is increasing and maps skills of the other type to tasks on the right hand side of the 
support. These two mapping functions generate two wage functions, one for each type of skills, that will in general overlap.

Dupuy (2007a) derives conditions under which technical change will lead to within wage inequality but not to between wage inequality (this characterizes the $70 \mathrm{~s}$ in the US). A family of closed form solutions for the wage functions is proposed. In this family, the production function of workermachine pairs is Cobb-Douglas, tasks are distributed according to a Beta distribution and the mapping functions have a logistic form. For some parameter values, one can derive analytically the shape of the wage functions in equilibrium and the distribution of wages within and between educational groups.

Regarding question 2, a general drawback of using production functions is that these functions lack micro-economic foundations that would enable us to justify our parametrization. Another very promising application of assignment models is in providing microeconomic foundations to aggregate production functions to understand what assumptions we make when assuming a CES production function with skill-labor augmenting technical change. In a first attempt to address this question, Dupuy and Marey (2008) used Rosen's (1978) tasks assignment ${ }^{9}$ model to show that while Katz and Murphy (1992), Acemoglu (2002) and the references therein, assume that sigma, i.e. the elasticity of substitution between skilled and unskilled workers, is constant over time, they implicitly assume that technical change increases relative productivity of skilled workers proportionally in every tasks leaving comparative advantage unaffected. The main problem with Rosen's approach, however, is that the shape of the production function is essentially driven by the relative (physical) productivity of skilled workers, which is rarely observed in data and hence requires using macroeconomic time series of relative wages and skill employment to look at changes in the elasticity of substitution (see Dupuy and Marey (2008) and Goldin and Katz (2007)). To overcome this issue, Dupuy (2007b), used a simplified version of the model developed in Dupuy (2007a) so that the shape of the production function is now driven by the distribution of tasks, which, using job titles for instance, could be proxied in many data sets. The model shows that assuming a constant elasticity of substitution over time is equivalent to assuming that the tasks distribution

\footnotetext{
${ }^{9}$ Rosen's (1978) tasks assignment model does not qualify as a two-sided atomeless assignment model for this model yields a partial equilibrium and workers within skills groups are homogenous (discrete heterogeneity).
} 
is constant over time, hence no job polarization. This results is in sharp contrast with the job polarization documented by Autor, Katz and Kearny (2006), Goos and Manning (2007), Spitz-Oener (2006), which suggests the use a CES production with variable elasticity of substitution over time to predict the schedule of the college premium over time.

\section{Summary}

This paper surveyed the literature about two-sided atomeless assignment models. Although in all models wage differentials arise from productivity differentials, two groups of models can be distinguished. The comparative advantage models consider that tasks can be performed by an indefinite number of workers but aggregate output is produced using fixed proportions of the output at each task. In contrast, in the scale of operations models, each task is associated with a machine that requires to be operated by a fixed number of workers to produce output, but aggregate output is obtained by summing up the output of each task. Both principles yield different wage functions in equilibrium even when the distribution of abilities and tasks and the production technology are identical. For a large (small) enough reservation wage, wage inequality will be larger (respectively smaller) in the comparative advantage model everywhere on the support of abilities. In the between, wage inequality will be larger at the bottom of the distribution but lower at the top for the comparative advantage model compared to the scale of operations model.

Assignment theory is arguably a very powerful tool to study (changes in) the wage structure. Assignment models allow to differentiate between changes coming from the distribution of skills (either school quality, environmental factors helping fostering abilities or genetics), the distribution of tasks (technical change, organizational change) or the productivity of worker-task pairs (technical change). Those few studies that investigated the impact of technical change on the wage structure using assignment models have shown two important results:

i. Skilled-biased technical change captured by an increase in the production function of worker-task pairs $r(v, t)$ over time will increase wage inequality over time. This result holds whether or not the production function is multiplicatively separable (no comparative advantage). 
ii. When the production function of worker-task pairs is multiplicatively separable, i.e. $r(v, t)=p(v) q(t)$, this skilled-biased technical change could manifest itself in the form of a rise in the performance of machines at constant characteristic $p(v)$ or in an increase in the performance differential of workers at constant ability $q^{\prime}(t)$.

However, little is know about the impact changes in the distribution of tasks on the structure of wages. Suen (2007) showed that an increase in the mean task will raise equilibrium wages of all workers but also raise wage differentials everywhere on the support of abilities and the wage of all workers will decrease as the distribution of tasks becomes more dispersed over time. However, Suen's (2007) results make only predictions about monotonic movements of wages for all workers but not about the dispersion of wages. The assignment literature is silent about the impact of an increase in the dispersion of tasks on wage inequality.

In this paper I also argue that research in the assignment theory literature should focus on:

1. Looking at the impact of an increase in the dispersion of tasks on wage inequality, building on Suen (2007)'s results,

2. Developing assignment models with multidimensional skills - to cope with the recent literature on the importance of non cognitive skills in wage formation-, endogenize the distribution of skills - to pin down the source of changes in the distribution of skills over time (genetics, environmental factors helping to foster abilities and quality of school) and hence changes in the wage structure--, building on Dupuy (2007a),

3. By their very microeconomic nature, the models could help linking macroeconomic concepts to microeconomic forces and hence provide a mean to evaluate how stringent macroeconomic assumptions are. For instance, Dupuy (2007b) shows how macroeconomic production function can be built from microeconomic forces like the distribution of tasks or skills.

\section{References}

Acemoglu, D. (2002): "Technical Change, Inequality and the Labor Market," Journal of Economic Literature, 40(1), 7-72. 
Autor, D. H., L. F. Katz, and M. S. Kearney (2006): "The Polarization of the U.S. Labor Market," American Economic Review, 96(2), $189-94$.

Burdett, K., And M. Coles (1997): "Marriage and Class," Quarterly Journal of Economics, 112, 141-68.

Costrell, R. M., And G. C. Loury (2004): "Distribution of Ability and Earnings in a Hierarchical Job Assignment Model," Journal of Political Economy, 112(6), 1322-1363.

Diamond, P. (1981): "Mobility Costs, Frictional Unemployment and Efficiency," Journal of Political Economy, 89, 798-812.

Dupuy, A. (2007a): "Educational Self-Selection, Tasks Assignment and Rising Wage Inequality," mimeo.

Dupuy, A. (2007b): "A Microfoundation for Production Functions: Assignment of Heterogenous Workers to Heterogenous Jobs," mimeo.

Dupuy, A., and P. Marey (2008): "Shifts and Twists in the Relative Productivity of Skilled Labor," Journal of Macroeconomics, forthcoming.

Fox, J. T. (2006): "Explaining Firm Size Wage Gaps with Equilibrium Hierarchies," unpublished manuscript.

Gabaix, X., And A. Landier (2008): "Why Has CEO Pay Increased So Much?," Quarterly Journal of Economics, forthcoming.

Garichno, L. (2000): "Hierarchies and the Organization of Knowledge in Production," Journal of Political Economy, 108(5), 874-904.

Garicano, L., and E. Rossi-Hansberg (2004): "Inequality and the Organization of Knowledge," American Economic Review, 94(2), 197-202.

(forthcoming): "Organization and Inequality in a Knowledge Economy," Quarterly Journal of Economics.

Goldin, C., And L. F. Katz (2007): "The Race between Education and Technology: The Evolution of U.S. Educational Wage Differentials, 1890 to 2005," NBER Working Papers 12984, National Bureau of Economic Research, Inc, available at http://ideas.repec.org/p/nbr/nberwo/12984.html. 
Goos, M., And A. Manning (2007): "Lousy and Lovely Jobs: The Rising Polarization of Work in Britain," The Review of Economics and Statistics, 89(1), 118-133.

Heckman, J. J., and Y. Rubinstein (2001): "The Importance of Noncognitive Skills: Lessons from the GED Testing Program," American Economic Review, 91(2), 145-149.

Jovanovic, B. (1979): "Job Matching and the Theory of Turnover," Journal of Political Economy, 87, 972-90.

Katz, L., And K. MurPhy (1992): "Changes in Relative Wages, 1963-1987: Supply and Demand Factors," Quarterly Journal of Economics, 107(1), $35-78$.

Lucas, R. E. (1978): "On the Size Distribution of Business Firms," Bell Journal of Economics, 9(2), 508-523.

Mortensen, D. (1986): "Job Search and Labor Market Analysis," in Handbook of Labor Economics, ed. by O. Ashenfelter, and R. Layard, vol. 2. Amsterdam: Northe Holland.

Pissarides, C. (1984): "Search Intensity, Job Advertising, and Efficiency," Journal of Labor Economics, 2, 128-43.

Rosen, S. (1978): "Substitution and the Division of Labor," Economica, 45, $235-50$.

Rosen, S. (1981): "The Economics of Superstars," American Economic Review, 71(5), 845-58.

_ (1982): "Authority, Control, and the Distribution of Earnings," Bell Journal of Economics, 13(2), 311-323.

Sattinger, M. (1975): "Comparative Advantage and the Distribution of Earnings and Abilities," Econometrica, 43(3), 455-68.

(1979): "Comparative Advantage and the Distributions of Earnings and Abilities," Econometrica, 43(3), 455-68.

Sattinger, M. (1984): "Factor Pricing in the Assignment Problem," Scandinavian Journal of Economics, 86(1), 17-34. 
Sattinger, M. (1993): "Assignment Models of the Distribution of Earnings," Journal of Economic Literature, 31(2), 831-80.

Sattinger, M. (1995): "Search and the Efficient Assignment of Workers to Jobs," International Economic Review, 36(2), 283-302.

Shimer, R. (2003): "Assignment and Unemployment," mimeo.

(2005): "The Assignment of Workers to Jobs in an Economy with Coordination Frictions," Journal of Political Economy, 113(5), 996-1025.

Shimer, R., And L. Smith (2000): "Assortative Matching and Search," Econometrica, 68(2), 343-370.

Spitz-Oener, A. (2006): "Technical Change, Job Tasks, and Rising Educational Demands: Looking Outside the Wage Structure," Journal of Labor Economics, 24(2), 235-70.

Suen, W. (2007): "The Comparative Statics of Differential Rents in TwoSided Matching Markets," Journal of Economic Inequality, 5, 149-58.

Terviö, M. (2008): "The Difference That CEOs Make: An Assignment Model Approach," American Economic Review, forthcoming.

Teulings, C. (1995b): "The Wage Distribution in a Model of the Assignment of Skills to Jobs," Journal of Political Economy, 103(2), 180-215.

(2005): "Comparative Advantage, Relative Wages, and the Accumulation of Human Capital," Journal of Political Economy, 113(2), 425-61.

Tinbergen, J. (1956): "On the Theory of Income Distribution," Weltwirtschaftliches Archiv, 77(1), 156-75. 
Table 1: Comparative advantage or scale of operations?

\begin{tabular}{|c|c|c|c|c|c|}
\hline & $\begin{array}{l}\text { Density } \\
\text { Workers } \\
s(t) \\
\end{array}$ & $\begin{array}{l}\text { Tasks } \\
d(v)\end{array}$ & $\begin{array}{l}\text { Productivity } \\
r(v, t)\end{array}$ & $\begin{array}{l}\text { Mapping } \\
v(t)\end{array}$ & $\begin{array}{l}\text { Wage Function } \\
w(t)\end{array}$ \\
\hline \multirow[t]{2}{*}{$\begin{array}{l}\text { Comparative Advantage } \\
\text { Scale of Operations }\end{array}$} & $\begin{array}{l}\frac{1}{\bar{t}-\underline{t}} \\
\frac{1}{t-\underline{t}}\end{array}$ & $\begin{array}{l}\frac{1}{\bar{v}-\underline{v}} \\
\frac{1}{\bar{v}-\underline{v}}\end{array}$ & $\begin{array}{l}\exp (\delta v t) \\
\exp (\delta v t)\end{array}$ & $\begin{array}{l}\Lambda t \\
\Lambda t\end{array}$ & $\begin{array}{l}\widetilde{w} \exp \left(\frac{\delta \Lambda}{2}\left(t^{2}-\underline{t}^{2}\right)\right) \\
\widetilde{w}+\frac{1}{2}\left(\exp \left(\delta \Lambda t^{2}\right)-\exp \left(\delta \Lambda \underline{t}^{2}\right)\right)\end{array}$ \\
\hline & \multicolumn{3}{|c|}{$\begin{array}{l}\text { Inverse wage function } \\
t(w)\end{array}$} & \multicolumn{2}{|c|}{$\begin{array}{l}\text { Wage density } \\
l(w)=s(t(w)) t^{\prime}(w)\end{array}$} \\
\hline $\begin{array}{l}\text { Comparative Advantage } \\
\text { Scale of Operations }\end{array}$ & \multicolumn{3}{|c|}{$\begin{array}{l}\left(\frac{2}{\delta \Lambda} \ln \frac{w}{\widetilde{w}}+\underline{t}^{2}\right)^{1 / 2} \\
\left(\frac{1}{\delta \Lambda} \ln \left(2(w-\widetilde{w})+\exp \left(\delta \Lambda \underline{t}^{2}\right)\right)\right)^{1 / 2}\end{array}$} & \multicolumn{2}{|c|}{$\begin{array}{l}\frac{1}{\delta \Lambda} \frac{1}{w} \frac{1}{t(w)} \\
\frac{1}{\delta \Lambda} \frac{1}{2(w-\widetilde{w})+\exp \left(\delta \Lambda \underline{t}^{2}\right)} \frac{1}{t(w)}\end{array}$} \\
\hline where $\Lambda=\frac{\bar{v}-\underline{v}}{\bar{t}-\underline{\underline{t}}}$ & & & & & \\
\hline
\end{tabular}


Panel a

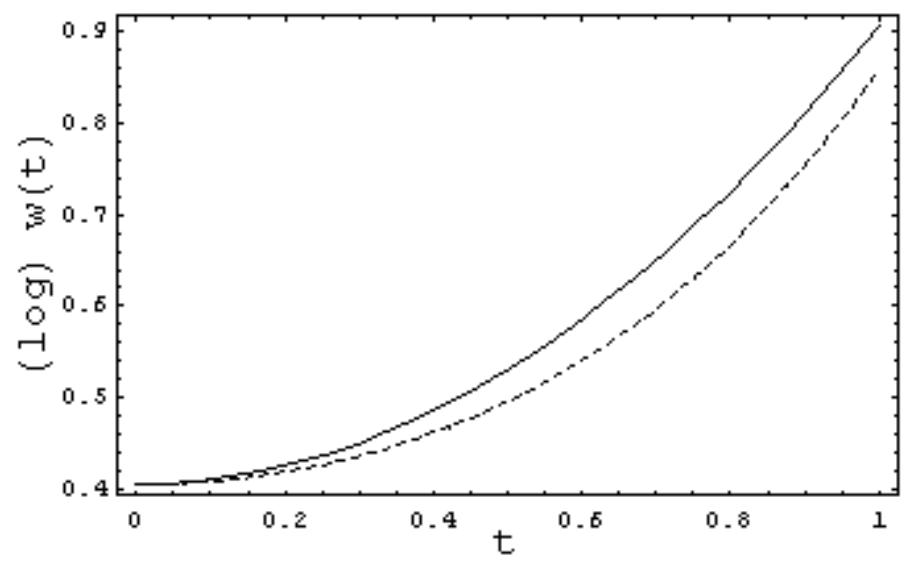

Panel b

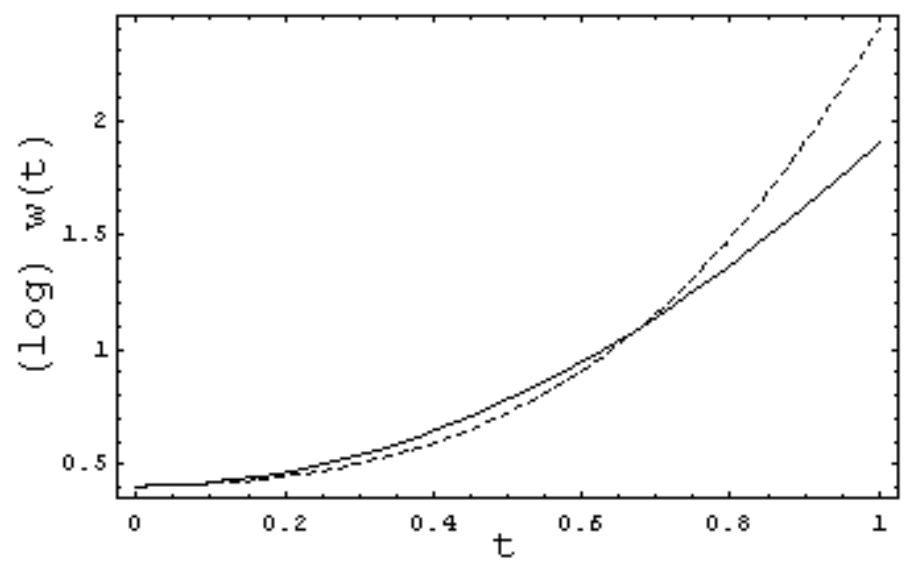

Figure 1: Wage as a function of skills under comparative advantage (full line) and scale of operations (dashed line) for two different technology parameter $\delta$. In both panels skills and tasks are uniformally distributed between 0 and 1 so that $\Lambda=1$ and the reservation wage is $\widetilde{w}=1.5$. Panel a was generated with technology $\delta=1$ while panel b was generated with technology $\delta=3$. 